\title{
Accuracy of low-density lipoprotein cholesterol estimation at very low levels
}

\author{
Renato Quispe ${ }^{1 *}$, Aditya Hendrani ${ }^{2}$, Mohamed B. Elshazly ${ }^{3}$, Erin D. Michos ${ }^{1,4}$, John W. McEvoy ${ }^{1,4}$, Michael J. Blaha ${ }^{1}$, \\ Maciej Banach ${ }^{5}$, Krishnaji R. Kulkarni ${ }^{6}$, Peter P. Toth ${ }^{1,7,8}$, Josef Coresh ${ }^{4}$, Roger S. Blumenthal ${ }^{1}$, Steven R. Jones ${ }^{1}$ \\ and Seth S. Martin ${ }^{1,4}$
}

\begin{abstract}
Background: As the approach to low-density lipoprotein cholesterol (LDL-C) lowering becomes increasingly intensive, accurate assessment of $L D L-C$ at very low levels warrants closer attention in individualized clinical efficacy and safety evaluation. We aimed to assess the accuracy of LDL-C estimation at very low levels by the Friedewald equation, the de facto clinical standard, and compare its accuracy with a novel, big data-derived LDL-C estimate.

Methods: In 191,333 individuals with Friedewald LDL-C $<70$ mg/dL, we compared the accuracy of Friedewald and novel LDL-C values in relation to direct measurements by Vertical Auto Profile ultracentrifugation. We examined differences (estimate minus ultracentrifugation) and classification according to levels initiating additional safety precautions per clinical practice guidelines.

Results: Friedewald values were less than ultracentrifugation measurement, with a median difference (25th to 75th percentile) of $-2.4(-7.4$ to 0.6$)$ at $50-69 \mathrm{mg} / \mathrm{dL},-7.0(-16.2$ to -1.2$)$ at $25-39 \mathrm{mg} / \mathrm{dL}$, and $-29.0(-37.4$ to -19.6$)$ at $<$ $15 \mathrm{mg} / \mathrm{dL}$. The respective values by novel estimation were -0.1 ( -1.5 to 1.3$),-1.1$ ( -2.5 to 0.3$)$, and -2.7 ( -4.9 to 0.0$)$ $\mathrm{mg} / \mathrm{dL}$. Among those with Friedewald $\mathrm{LDL}-\mathrm{C}<15,15$ to $<25$, and 25 to $<40 \mathrm{mg} / \mathrm{dL}$, the classification was discordantly low in $94.9 \%, 82.6 \%$, and $59.9 \%$ of individuals as compared with $48.3 \%, 42.4 \%$, and $22.4 \%$ by novel estimation.

Conclusions: Estimation of even lower LDL-C values (by Friedewald and novel methods) is even more inaccurate. More often than not, a Friedewald value $<40 \mathrm{mg} / \mathrm{dL}$ is underestimated, which translates into unnecessary safety alarms that could be reduced in half by estimation using our novel method.
\end{abstract}

Keywords: Low-density lipoprotein cholesterol, Very low, Accuracy, Friedewald estimation, Novel method, Clinical decision making

\section{Background}

The critical importance of low-density lipoprotein cholesterol (LDL-C) lowering in cardiovascular disease management and prevention of atherothrombotic events is well established [1-7]. LDL-C is the lipid parameter that is most widely used to guide clinical decision making. Most major international guidelines endorse an LDL-C target of $<70 \mathrm{mg} / \mathrm{dL}$ for high-risk patients [8-10] and the IMProved Reduction of Outcomes: Vytorin Efficacy

\footnotetext{
* Correspondence: jquispe1@jhmi.edu

${ }^{1}$ Ciccarone Center for the Prevention of Heart Disease, Division of Cardiology, Department of Medicine, Johns Hopkins University School of Medicine, 600 N. Wolfe Street, Carnegie 591, Baltimore, MD 21287, USA

Full list of author information is available at the end of the article
}

International Trial (IMPROVE-IT) trial [11] showed additional benefit from attaining even lower LDL-C levels $(\sim 50 \mathrm{mg} / \mathrm{dL})$ by adding ezetimibe to statin therapy. As more aggressive LDL-C lowering approaches become increasingly common, with use of human monoclonal antibodies targeting proprotein convertase subtilisin-kexin type 9 (PCSK9) [12-14], the accuracy of LDL-C assessment at very low levels gains importance.

There is little experience in managing patients with very low LDL-C and considerable concern has arisen about whether the benefit-to-risk ratio for lowering LDL-C holds at these very low levels. Thus far, safety data have been reassuring with respect to achievement of very low LDL-C with PCSK9 inhibitors. However, 
there remains a need for longer term safety data in humans with low LDL-C levels outside of those with genetically low LDL-C $[15,16]$. With a median follow-up of 6 years, IMPROVE-IT provides the most important and reassuring data to date [11]. The 2013 ACC/AHA cholesterol guidelines recommended considering statin dose down-titration at LDL-C $<40 \mathrm{mg} / \mathrm{dL}$ [17]. In phase 3 trials of some PCSK9 inhibitors, active safety monitoring was closely performed if on-treatment LDL-C levels were $<$ $25 \mathrm{mg} / \mathrm{dL}$, and medication was stopped at $<15 \mathrm{mg} / \mathrm{dL}$ [18]. In the ODYSSEY OUTCOMES trial, the investigators are specifically avoiding LDL-C levels $<15$, adjusting alirocumab to achieve LDL-C 15 to $<50 \mathrm{mg} / \mathrm{dL}$. The Food and Drug Administration (FDA) recommended close monitoring for adverse events at these very low LDL-C levels in order to track any potential long-term safety effects $[14,18]$. Therefore, accurate assessment of LDL-C at very low levels is directly tied to the accuracy of therapeutic dosing and the attention to safety monitoring.

No accurate direct LDL-C assay is widely available in clinical practice. Direct chemical assays of LDL-C, though widely available, have repeatedly shown inaccurate results [19-22]. Ultracentrifugation is the gold standard for direct measurement, but is resource intensive and available in few laboratories. Thus, Friedewald-estimation of LDL-C (LDLf-C), derived from 448 patients in 1972 [23], is the de facto clinical standard. The Friedewald method converts triglycerides (TG) to very-low density lipoprotein cholesterol (VLDL-C) assuming a fixed factor of 5 for the TG:VLDL-C ratio (in mg/dL).

Friedewald estimation generally provides an accurate result in patients with moderate and high LDL-C levels and well-controlled TG levels $(<150 \mathrm{mg} / \mathrm{dL})$. However, in patients with low LDL-C, a group largely outside the range of the Friedewald derivation sample, and elevated TG, the Friedewald equation tends to significantly underestimate LDL-C levels [24, 25]. A small study recently suggested that this problem may be magnified in individuals with very low LDL-C levels [26].

In contrast to the Friedewald method, our group previously used an unbiased big data approach to develop a novel method, published in 2013 [27], that accounts for patient heterogeneity by incorporating an adjustable TG:VLDL-C ratio [27]. The adjustable factors were derived from our previously reported 180-cell method, whereby TG and non-HDL-C were used to determine patient-specific flexible ratios to estimate VLDL-C. This novel method appears to provide a more accurate estimate, but its comparative performance has not been specifically assessed throughout a range of clinically relevant very low LDL-C levels, and in particular, at LDL-C less than $70 \mathrm{mg} / \mathrm{dL}$.

Therefore, in a large contemporary population with very low LDL-C levels $(<70 \mathrm{mg} / \mathrm{dL})$, we aimed to assess and compare the accuracy of Friedewald and novel LDL$\mathrm{C}$ estimation in absolute terms and according to clinical categories.

\section{Methods \\ Study population}

We examined consecutive lipid profiles from US patients aged 18 years or older in the Very Large Database of Lipids, which has lipid distributions that are similar to the National Health and Nutrition Examination Survey population (NHANES) 2007-2008 [28]. Each patient had a Vertical Auto Profile (VAP, Atherotech Diagnostics Lab, Birmingham, Alabama) from 2009 to 2011 for clinical reasons. We excluded patients with $\mathrm{TG} \geq$ $400 \mathrm{mg} / \mathrm{dL}$, according to specifications of the Friedewald equation [23].

The Johns Hopkins institutional review board waved the requirement of informed consent and declared our study exempt as we used only de-identified data routinely collected during clinical lipid determinations. The Very Large Database of Lipids and its studies are registered on clinicaltrials.gov (NCT01698489). This is phase C of study 1 (VLDL-1C).

\section{Lipid measurements}

The VAP test separates lipoproteins by density gradient ultracentrifugation, then uses a colorimetric method of cholesterol determination [29]. This methodology has been developed using fractions from sequential flotation method [30, 31]. The accuracy and precision of VAP lipid parameters have been validated against $\beta$ quantification at Washington University's Core Laboratory for Clinical Studies (St. Louis, Missouri), showing a correlation coefficient (R) of 0.980 for LDL-C [29]. Of note, the VAP method was subjected to a new lab validation, in which an experiment was performed by running VAP assays using serially increasing amounts of pooled serum $(5-200 \mu \mathrm{L})$. LDL-C was very linear throughout the tested range of 9 to $520 \mathrm{mg} / \mathrm{dL}$. On the other hand, TG levels were directly measured using the Abbott ARCHITECT C-8000 system (Abbott Laboratories, Abbott Park, Illinois). Further details about the validation of VAP lipid parameters have been previously described [29].

\section{Study variables}

Directly-measured LDL-C (LDLd-C) via ultracentrifugation was considered the gold standard. LDLf-C was estimated as total cholesterol minus HDL-C minus TG/5, in $\mathrm{mg} / \mathrm{dL}$. Novel LDL-C (LDLn-C) was estimated using 1 of 180 different factors for the TG/VLDL-C ratio, according to non-HDL-C and TG levels [27]. This method has undergone independent external validation by groups 
inside and outside the US, and showed improvements over Friedewald estimation in those studies [32, 33].

\section{Statistical analysis}

First, we used scatter plots and Bland-Altman plots to visually assess discordance between LDL-C values and LDLd-C in the overall population and by TG categories. We also calculated correlation between LDL-C values and direct LDL-C through spearman's Rho. Next, we calculated differences between LDL-C values and LDLd-C (LDLf-C minus LDLd-C and LDLn-C minus LDLd-C), so that negative values represent underestimation, and positive values represent overestimation. Medians (2575th percentile) were calculated and compared using the Kruskal-Wallis test. Since the performance of Friedewald estimation is TG dependent, we also performed analyses by three TG categories: < 150, 150-199, and 200-399 mg/dL.

Additionally, according to clinically-relevant LDL-C categories, we determined proportions of concordance between estimated and directly-measured LDL-C. When discordance was present, we labeled an LDL-C estimate as discordantly low if it was in a lower category than LDLd-C, and vice versa for discordantly high. Cohen's Kappa statistics (95\% CI) were calculated for agreement between values and direct LDL-C measurement. The five LDL-C cut-off points used to define categories were: 15 , $25,40,50$, and $70 \mathrm{mg} / \mathrm{dL}$, corresponding to $<0.1 \mathrm{th}, 0.2 \mathrm{th}$, 1.3th, 3.6th, and 14.7th percentiles in our study population, respectively. The 15 and $25 \mathrm{mg} / \mathrm{dL}$ levels were selected based on their use in clinical trial protocols of
PCSK9 inhibitors, the $40 \mathrm{mg} / \mathrm{dL}$ cut-off point because of the class IIb recommendation in the ACC/AHA guidelines to consider statin down-titration below this level, the $50 \mathrm{mg} / \mathrm{dL}$ level as this is an emerging clinical target based on the IMPROVE-IT trial, and $70 \mathrm{mg} / \mathrm{dL}$ as an established goal in multiple guidelines.

Statistical analyses of numerical data were performed in Stata version 13.0 (StataCorp LP, College Station, Texas). Logarithmically scaled pseudocolor-encoded data density plots were generated in $\mathrm{R}$ Version 2.15.1 (Vienna, Austria) using the IDPmisc package.

\section{Results}

\section{Patient characteristics}

In $1,310,440$ patients with TG $<400 \mathrm{mg} / \mathrm{dL}, 191,333 \mathrm{had}$ LDLf-C $<70 \mathrm{mg} / \mathrm{dL}, 153,917$ had LDLn-C $<70 \mathrm{mg} / \mathrm{dL}$, and 154,725 had LDLd-C $<70 \mathrm{mg} / \mathrm{dL}$ (Table 1). Among patients with LDLf-C $<70 \mathrm{mg} / \mathrm{dL}$, the proportion with TG levels 200-399 mg/dL increased as LDLf-C levels decreased, reaching $81.3 \%$ in patients with LDLf-C $<$ $15 \mathrm{mg} / \mathrm{dL}$. In contrast, only $16.9 \%$ of those with LDLn$\mathrm{C}<15 \mathrm{mg} / \mathrm{dL}$ and $4.4 \%$ with LDLd-C $<15 \mathrm{mg} / \mathrm{dL}$ had TG levels of 200-399 mg/dL. In patients with LDLd-C $<70 \mathrm{mg} / \mathrm{dL}$, the vast majority had TG levels $<150 \mathrm{mg} /$ dL (Table 1).

\section{Correlation between LDL-C values and direct ultracentri- fugation measurement}

Overall, LDLd-C appeared more strongly correlated with LDLn-C (Rho $\left.=0.9401, P<10^{-15}\right)$ than with

Table 1 Distribution of individuals with very low LDL-C levels across LDL-C and TG categories

\begin{tabular}{|c|c|c|c|c|c|c|}
\hline \multirow[t]{2}{*}{ TG (mg/dL) } & \multicolumn{6}{|c|}{ Friedewald-estimated LDL-C (mg/dL) } \\
\hline & $<15$ & 15 to $<25$ & 25 to $<40$ & 40 to $<50$ & 50 to $<70$ & Total \\
\hline$<150$ & $82(9.9)$ & $716(33.0)$ & $7591(52.9)$ & $18,986(64.6)$ & $103,096(71.3)$ & $130,471(68.2)$ \\
\hline $150-199$ & $73(8.8)$ & $325(15.0)$ & $2370(16.5)$ & $4504(15.3)$ & $20,485(14.2)$ & $27,757(14.5)$ \\
\hline 200-399 & $672(81.3)$ & $1126(52.0)$ & $4385(30.6)$ & $5918(20.1)$ & $21,004(14.5)$ & $33,105(17.3)$ \\
\hline Total & $827(0.4)$ & $2167(1.1)$ & $14,346(7.5)$ & $29,408(15.4)$ & $144,585(75.6)$ & 191,333 \\
\hline \multirow[t]{2}{*}{$\mathrm{TG}(\mathrm{mg} / \mathrm{dL})$} & \multicolumn{6}{|c|}{ Novel method-estimated LDL-C (mg/dL) } \\
\hline & $<15$ & 15 to $<25$ & 25 to $<40$ & 40 to $<50$ & 50 to $<70$ & Total \\
\hline$<150$ & $90(76.3)$ & $638(81.3)$ & $7067(83.3)$ & $17,708(82.9)$ & $98,868(80.3)$ & $124,371(80.8)$ \\
\hline $150-199$ & $8(6.8)$ & $71(9.0)$ & $788(9.3)$ & $2146(10.1)$ & $13,157(10.7)$ & $16,170(10.5)$ \\
\hline $200-399$ & $20(16.9)$ & $76(9.7)$ & $630(7.4)$ & $1506(7.0)$ & $11,144(9.0)$ & $11,144(98.7)$ \\
\hline Total & $118(0.1)$ & $785(0.5)$ & $8485(5.5)$ & $21,360(13.9)$ & $123,169(80.0)$ & 153,917 \\
\hline \multirow[t]{2}{*}{$\mathrm{TG}(\mathrm{mg} / \mathrm{dL})$} & \multicolumn{6}{|c|}{ Directly-measured LDL-C (mg/dL) } \\
\hline & $<15$ & 15 to $<25$ & 25 to $<40$ & 40 to $<50$ & 50 to $<70$ & Total \\
\hline$<150$ & $64(94.1)$ & $500(85.8)$ & $6328(82.4)$ & $16,744(81.0)$ & $100,149(79.7)$ & $123,785(80.0)$ \\
\hline 150-199 & $1(1.5)$ & $42(7.2)$ & 704 (9.2) & $2121(10.3)$ & $14,347(11.4)$ & $17,215(11.1)$ \\
\hline 200-399 & $3(4.4)$ & $41(7.0)$ & $648(8.4)$ & $1803(8.7)$ & $11,230(8.9)$ & $13,725(8.9)$ \\
\hline Total & $68(<0.1)$ & $583(0.4)$ & $7680(5.0)$ & 20,668 (13.3) & $125,726(81.3)$ & 154,725 \\
\hline
\end{tabular}

Numbers shown are $\mathrm{n}$ with column percentages in parentheses 
LDLf-C (Rho $=0.7408, P<10^{-15}$ ) at LDL-C $<70 \mathrm{mg} /$ dL (Figs. 1a vs. 2a). This difference in correlation was more apparent at higher TG levels (Figs. 1b-d vs. 2b-d). Bland-Altman plots also showed a higher agreement of LDLd-C with LDLn-C, than with LDLf$\mathrm{C}$ (Additional file 1: Figure S1).

\section{Differences between LDL-C values and direct ultracentri- fugation measurement}

Friedewald values were lower than direct measurement, with a median difference $(25-75$ th $)$ of -2.4 ( -7.4 to $0.6)$ at $50-69 \mathrm{mg} / \mathrm{dL},-7.0(-16.2$ to -1.2$)$ at $25-$ $39 \mathrm{mg} / \mathrm{dL}$, and $-29.0(-37.4$ to -19.6$)$ at $<15 \mathrm{mg} / \mathrm{dL}$. Respective values by novel estimation were $-0.1(-1.5$ to 1.3$),-1.1$ ( -2.5 to 0.3 ), and -2.7 ( -4.9 to 0.0$) \mathrm{mg} / \mathrm{dL}$ (Table 2). Differences were larger at higher TG levels. For example, at LDLf-C 50-69 $\mathrm{mg} / \mathrm{dL}$, the difference was $-0.6(-3.2$ to 1.4$) \mathrm{mg} / \mathrm{dL}$ at $\mathrm{TG}<150$, and -17.0 (22.6 to -12.4$) \mathrm{mg} / \mathrm{dL}$ at TG 200-399. This TGdependent effect was not seen using novel estimation with respective values of $-0.2(-1.4$ to 1.1$)$ and -0.2 (3.8 to 3.6$)$. Medians were significantly different across groups $(P<0.0001)$.

\section{Discordance of individuals across clinically relevant, very low LDL-C categories}

Almost one in every four individuals $(22.9 \%)$ with LDLf$\mathrm{C}<70 \mathrm{mg} / \mathrm{dL}$, but only one in $16(6.3 \%)$ with LDLn-C $<$ $70 \mathrm{mg} / \mathrm{dL}$, had LDLd-C $\geq 70 \mathrm{mg} / \mathrm{dL}$. Discordantly high $\mathrm{LDL}-\mathrm{C}$ values were uncommon $(0.9 \%$ for $\mathrm{LDLn}-\mathrm{C}$ and $0.6 \%$ for LDLf-C).

The proportion of individuals with discordantly low LDLf-C increased at lower levels and, more often than not, those with LDLf-C $<40 \mathrm{mg} / \mathrm{dL}$ had LDLd-C in a higher clinical category (Table 3 ). For the $<15,15$ to $<25,25$ to $<40,40$ to $<50$, and 50 to $<70 \mathrm{mg} / \mathrm{dL}$ LDLf-C categories, discordantly low proportions were $94.9 \%, 82.6 \%, 59.9 \%, 52.7 \%$, and $28.7 \%$, respectively. Cohen's Kappa index was 0.746 (0.7460.747, $P<0.00001$ ).

On the other hand, concordance between LDLn-C and LDLd-C was significantly higher. The discordant proportion was never greater than $50 \%$ at these very low LDL-C categories. For the $<15,15$ to $<25,25$ to $<40,40$ to $<50$, and 50 to $<70 \mathrm{mg} / \mathrm{dL}$ categories, discordantly low proportions were 48.3\%, 42.4\%, 22.4\%, $20.1 \%$, and $7.8 \%$, respectively. Cohen's Kappa index was $0.892(0.891-0.893, P<0.00001)$.

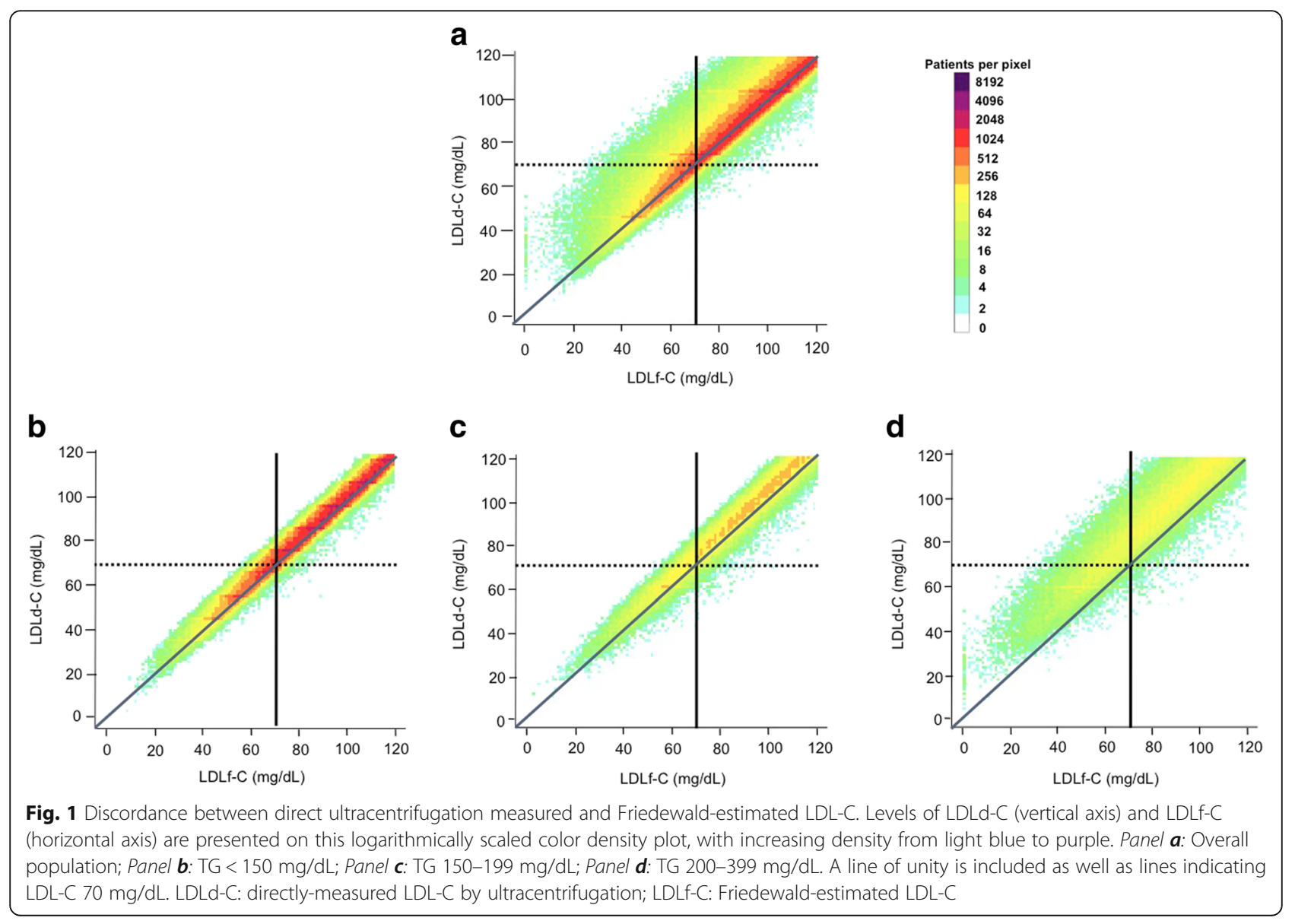




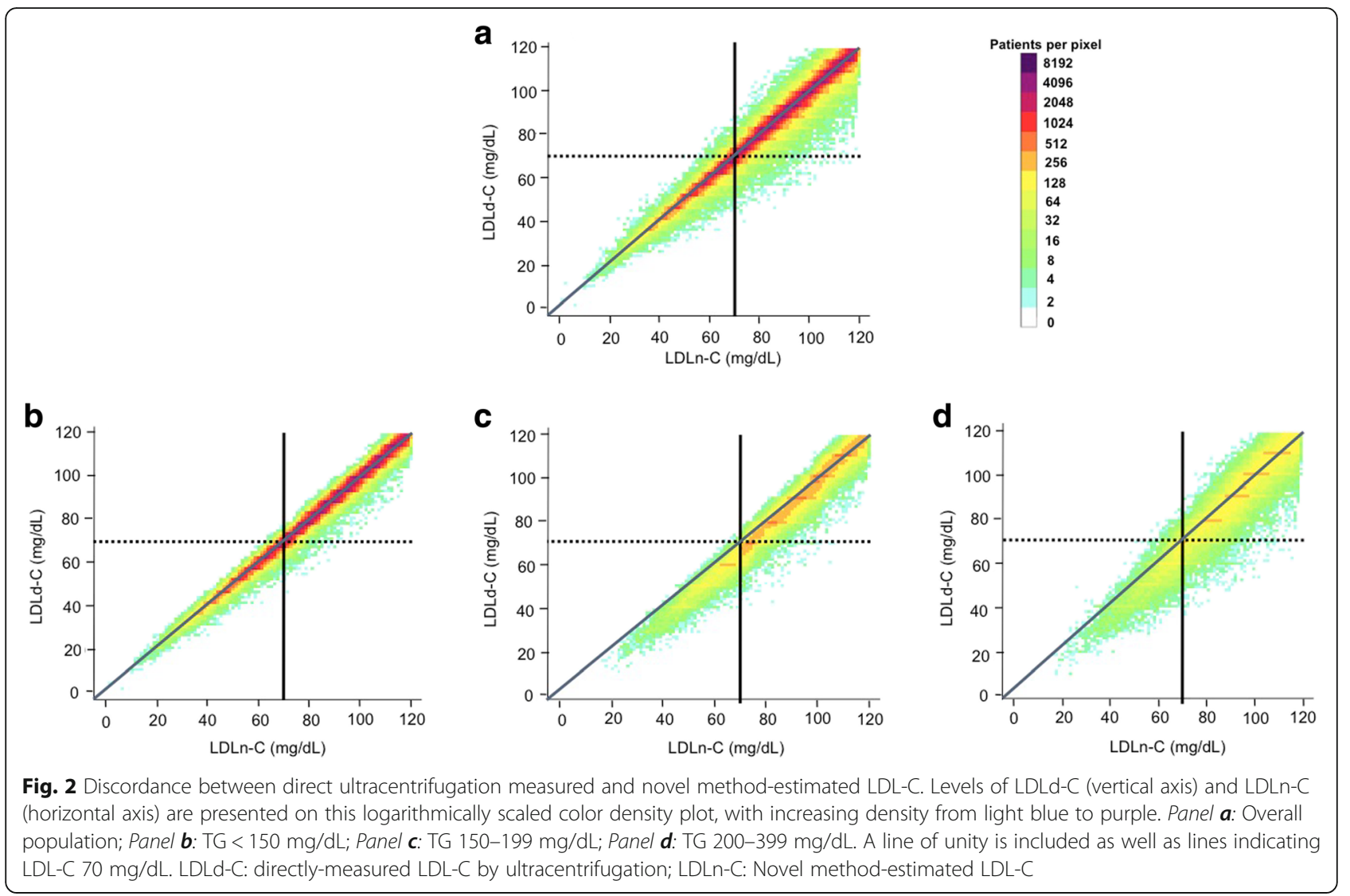

When LDLn-C was discordantly low, it was nearly always low by a difference of one clinical category (i.e., 40 to $<50$ and 50 to $<70 \mathrm{mg} / \mathrm{dL}$ ). In contrast, when LDLf-C was low, it was frequently low by 2 or even 3 clinical categories as compared to ultracentrifugation measured LDL-C.

\section{Discordance across LDL-C categories by TG levels}

Having a discordantly low LDL-C estimate was significantly more common at higher TG levels, reaching up to $39.0 \%$ and $59.4 \%$ for LDLf-C, and $7.8 \%$ and $16.6 \%$ for LDLn-C at TG $150-199$ and $200-399 \mathrm{mg} / \mathrm{dL}$, respectively. Of note, in patients with TG levels of 150-199 and 200-399 mg/DL, the number of individuals with LDLf-C $<15 \mathrm{mg} / \mathrm{dL}$ but LDLd-C $\geq 15 \mathrm{mg} / \mathrm{dL}$ (Additional file 2: Table S1) was approximately 9 and 30 times higher, respectively, compared to those with LDLn-C $<15 \mathrm{mg} / \mathrm{dL}$ but LDLd-C $\geq 15 \mathrm{mg} / \mathrm{dL}$ (Additional file 3: Table S2).

\section{Discussion}

In an analysis comprising a uniquely large number of individuals with very low LDL-C levels, our data show that estimation of even lower LDL-C levels is even more inaccurate. This study expands upon our prior work in the Very Large Database of Lipids [24] by closely examining the accuracy of LDL-C within the very low range. More often than not, LDL-C levels estimated by the Friedewald equation are classified falsely low if $<40 \mathrm{mg} / \mathrm{dL}$, when accurate safety monitoring is most needed, and this proportion exceeds $80 \%$ at $\mathrm{TG} \geq 150 \mathrm{mg} / \mathrm{dL}$. Although estimation of LDL-C remains imperfect by the novel method, it provides a substantially more accurate estimation than the Friedewald equation at very low LDL-C levels, halving the proportion of falsely low classifications.

\section{Implications for efficacy and safety assessment}

The IMPROVE-IT trial [11] testing the addition of ezetimibe to statin therapy helped confirm the "the lower the better" hypothesis and supports aiming for lower LDL-C levels if it can preserve a favorable risk-benefit ratio [34]. Moreover, recently FDA approved monoclonal antibodies to PCSK9 appear safe through 1 year and robustly lower LDL-C [35]. The addition of alirocumab and evolocumab to standard of care in the ODYSSEY LONG-TERM and Open Label Study of Long Term Evaluation Against LDL-C Trial (OSLER) studies, respectively, yielded mean LDL-C reductions of approximately $60 \%$ to levels of approximately $50 \mathrm{mg} / \mathrm{dL}$ and preliminary short-term outcome data show an incremental $50 \%$ relative reduction in cardiovascular events 


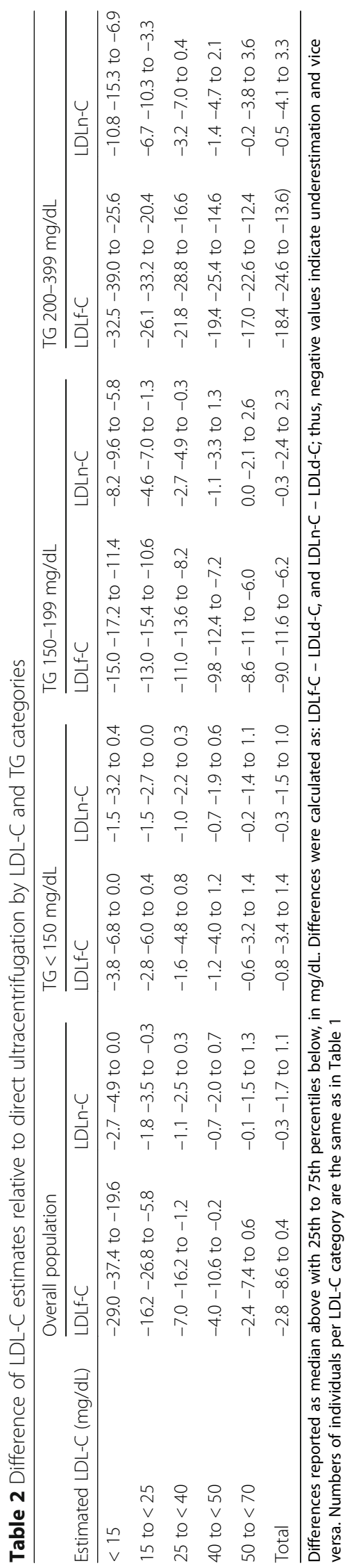


Table 3 Proportions of concordance between estimation methods and direct ultracentrifugation LDL-C

\begin{tabular}{|c|c|c|c|c|c|c|c|c|}
\hline \multicolumn{9}{|c|}{ Direct Ultracentrifugation Measured LDL-C; mg/dL } \\
\hline & & $<15$ & $\begin{array}{c}15 \text { to } \\
<25\end{array}$ & $\begin{array}{c}25 \text { to } \\
<40\end{array}$ & $\begin{array}{c}40 \text { to } \\
<50\end{array}$ & $\begin{array}{c}50 \text { to } \\
<70\end{array}$ & $\geq 70$ & Total \\
\hline \multirow{6}{*}{$\begin{array}{c}\text { Friedewald } \\
\text { Estimated } \\
\text { LDL-C; } \\
\text { mg/dL }\end{array}$} & $<15$ & $\begin{array}{c}42 \\
(5.1)\end{array}$ & $\begin{array}{c}116 \\
(14.0)\end{array}$ & $\begin{array}{c}364 \\
(44.0)\end{array}$ & $\begin{array}{c}201 \\
(24.3)\end{array}$ & $\begin{array}{c}103 \\
(12.5)\end{array}$ & $\begin{array}{c}1 \\
(0.1)\end{array}$ & 827 \\
\hline & $\begin{array}{c}15 \text { to } \\
<25\end{array}$ & $\begin{array}{c}26 \\
(1.2)\end{array}$ & $\begin{array}{c}352 \\
(16.2)\end{array}$ & $\begin{array}{c}827 \\
(38.1)\end{array}$ & $\begin{array}{c}519 \\
(24.0)\end{array}$ & $\begin{array}{c}431 \\
(19.9)\end{array}$ & $\begin{array}{c}12 \\
(0.6)\end{array}$ & 2,167 \\
\hline & $\begin{array}{c}25 \text { to } \\
<40\end{array}$ & $\begin{array}{c}0 \\
(0.0)\end{array}$ & $\begin{array}{c}115 \\
(0.8)\end{array}$ & $\begin{array}{l}5,637 \\
(39.3)\end{array}$ & $\begin{array}{l}4,724 \\
(32.9)\end{array}$ & $\begin{array}{l}3,452 \\
(24.1)\end{array}$ & $\begin{array}{c}418 \\
(2.9)\end{array}$ & 14,346 \\
\hline & $\begin{array}{l}40 \text { to } \\
<50\end{array}$ & $\begin{array}{c}0 \\
(0.0)\end{array}$ & $\begin{array}{c}0 \\
(0.0)\end{array}$ & $\begin{array}{l}835 \\
(2.9)\end{array}$ & $\begin{array}{c}13,061 \\
(44.4)\end{array}$ & $\begin{array}{c}13,742 \\
(46.7)\end{array}$ & $\begin{array}{l}1,770 \\
(6.0)\end{array}$ & 29,408 \\
\hline & $\begin{array}{c}50 \text { to } \\
<70\end{array}$ & $\begin{array}{c}0 \\
(0.0)\end{array}$ & $\begin{array}{c}0 \\
(0.0)\end{array}$ & $\begin{array}{c}16 \\
(<0.1)\end{array}$ & $\begin{array}{c}2,156 \\
(1.5)\end{array}$ & $\begin{array}{c}100,878 \\
(69.8)\end{array}$ & $\begin{array}{c}41,535 \\
(28.7)\end{array}$ & 144,585 \\
\hline & $\geq 70$ & $\begin{array}{c}0 \\
(0.0)\end{array}$ & $\begin{array}{c}0 \\
(0.0)\end{array}$ & $\begin{array}{c}1 \\
(<0.1)\end{array}$ & $\begin{array}{c}7 \\
(<0.1)\end{array}$ & $\begin{array}{l}7,120 \\
(0.6)\end{array}$ & $\begin{array}{c}1,111,971 \\
(99.4)\end{array}$ & $1,119,099$ \\
\hline
\end{tabular}

\begin{tabular}{|c|c|c|c|c|c|c|c|c|}
\hline \multirow{7}{*}{$\begin{array}{c}\text { Novel } \\
\text { Method } \\
\text { Estimated } \\
\text { LDL-C; } \\
\text { mg/dL }\end{array}$} & $<15$ & $\begin{array}{c}61 \\
(51.7)\end{array}$ & $\begin{array}{c}53 \\
(44.9)\end{array}$ & $\begin{array}{c}4 \\
(3.4)\end{array}$ & $\begin{array}{c}0 \\
(0.0)\end{array}$ & $\begin{array}{c}0 \\
(0.0)\end{array}$ & $\begin{array}{c}0 \\
(0.0)\end{array}$ & 118 \\
\hline & $\begin{array}{l}15 \text { to } \\
<25\end{array}$ & $\begin{array}{c}7 \\
(0.9)\end{array}$ & $\begin{array}{c}445 \\
(56.7)\end{array}$ & $\begin{array}{c}330 \\
(42.0)\end{array}$ & $\begin{array}{c}3 \\
(0.4)\end{array}$ & $\begin{array}{c}0 \\
(0.0)\end{array}$ & $\begin{array}{c}0 \\
(0.0)\end{array}$ & 785 \\
\hline & $\begin{array}{c}25 \text { to } \\
<40\end{array}$ & $\begin{array}{c}0 \\
(0.0)\end{array}$ & $\begin{array}{c}85 \\
(1.0)\end{array}$ & $\begin{array}{c}6,499 \\
(76.6)\end{array}$ & $\begin{array}{l}1,878 \\
(22.1)\end{array}$ & $\begin{array}{c}23 \\
(0.3)\end{array}$ & $\begin{array}{c}0 \\
(0.0)\end{array}$ & 8,485 \\
\hline & $\begin{array}{c}40 \text { to } \\
<50\end{array}$ & $\begin{array}{c}0 \\
(0.0)\end{array}$ & $\begin{array}{c}0 \\
(0.0)\end{array}$ & $\begin{array}{c}748 \\
(3.5)\end{array}$ & $\begin{array}{l}16,314 \\
(76.4)\end{array}$ & $\begin{array}{l}4,296 \\
(20.1)\end{array}$ & $\begin{array}{c}2 \\
(<0.1)\end{array}$ & 21,360 \\
\hline & $\begin{array}{l}50 \text { to } \\
<70\end{array}$ & $\begin{array}{c}0 \\
(0.0)\end{array}$ & $\begin{array}{c}0 \\
(0.0)\end{array}$ & $\begin{array}{c}92 \\
(0.1)\end{array}$ & $\begin{array}{c}2,408 \\
(2.0)\end{array}$ & $\begin{array}{c}110,985 \\
(90.1)\end{array}$ & $\begin{array}{l}9,684 \\
(7.8)\end{array}$ & 123,169 \\
\hline & $\geq 70$ & $\begin{array}{c}0 \\
(0.0)\end{array}$ & $\begin{array}{c}0 \\
(0.0)\end{array}$ & $\begin{array}{c}7 \\
(<0.1)\end{array}$ & $\begin{array}{c}65 \\
(<0.1)\end{array}$ & $\begin{array}{c}10,422 \\
(0.9)\end{array}$ & $\begin{array}{c}1,146,021 \\
(99.1)\end{array}$ & $1,156,515$ \\
\hline & Total & 68 & 583 & 7,680 & 20,668 & 125,726 & $1,155,707$ & $1,310,432$ \\
\hline
\end{tabular}


compared to standard of care [12, 13]. A meta-analysis found that PCSK9 inhibitors reduced all-cause mortality (OR, 0.45; CI, 0.23-0.86) [35], and long-term outcome trials are eagerly awaited [36-39].

An eligibility criterion for those long-term trials is an on-treatment LDL-C $\geq 70 \mathrm{mg} / \mathrm{dL}$. Based on our data, $29 \%$ of persons with Friedewald LDL-C levels of 50 $69 \mathrm{mg} / \mathrm{dL}$ actually have a directly-measured LDL-C $\geq$ $70 \mathrm{mg} / \mathrm{dL}$. Therefore, individuals may be excluded from the long-term trials because of an underestimated LDL$\mathrm{C}$ level. These trials are focused on high-risk patients, one feature of which is a concurrently high TG level, a setting wherein LDL-C underestimation is more likely to occur by Friedewald estimation.

For those patients who do qualify for trial participation or receive therapies in routine practice to treat their LDL-C down to very low levels, extra concern over ensuring appropriate risk-benefit ratio is warranted. This issue was raised in recent FDA advisory deliberations on PCSK9 inhibitors and some PCSK9 inhibitor trial protocols included active safety monitoring for LDL-C levels $<25 \mathrm{mg} / \mathrm{dL}$ and drug discontinuation when LDL-C was $<15 \mathrm{mg} / \mathrm{dL}[14,18]$. Since these LDL-C cut-off points were not derived from Friedewald LDL-C values, our findings raise the question of potential misinformed decision making due to LDL-C underestimation when relying on the Friedewald equation. This might translate into undue anxiety, increased resource utilization (e.g., clinic visits, additional lab work), and inappropriate therapeutic adjustment.

The association between very low LDL-C levels and adverse events has been controversial. Although the Pravastatin or Atorvastatin Evaluation and Infection Therapy (PROVE-IT) study demonstrated augmented risk reduction without safety concerns among participants with LDL-C $<40 \mathrm{mg} / \mathrm{dL}$ [40], a post-hoc analysis of the Justification for the Use of Statins in Primary Prevention: An Intervention Trial Evaluating Rosuvastatin (JUPITER) trial showed a significantly higher incidence of new-onset diabetes, hematuria, and hepatobiliary disorders in rosuvastatin-treated participants with LDL-C $\leq$ $30 \mathrm{mg} / \mathrm{dL}$ as compared to rosuvastatin-treated participants with LDL-C $>30 \mathrm{mg} / \mathrm{dL}$ and placebo-allocated participants [41]. Of note, LDL-C was estimated by Friedewald equation, and therefore more than $50 \%$ of values were discordantly low based on our results. In a recent meta-analysis, PCSK9 therapy was associated with a significant increase in neurocognitive adverse events compared with placebo, although this number was yet small [16]. However, this preliminary finding is still undergoing further investigation.

Several PCSK9 trials directly measured LDL-C by ultracentrifugation at different time points to support treatment effect data obtained using the Friedewald equation
[14]. In trials of alirocumab [13] and evolocumab [42], the placebo-subtracted percentage change in LDLf-C was 2$4 \%$ greater than that of direct LDL-C, consistent with modest group averaged LDL-C underestimation at lower LDL-C levels in follow-up (in patients with generally well controlled TG levels). However, actual difference between LDLf-C and direct LDL-C in the patient was not evaluated as we have done in this study. While accurate measurement of LDL-C is important in accurately assessing group averaged treatment effects in clinical trials, it is also important for accurate patient-level monitoring of adverse events at very low LDL-C levels $(<25 \mathrm{mg} / \mathrm{dL})$ as suggested by the FDA [14]. For example, approximately $40 \%$ and $26 \%$ of trial participants using alirocumab [18] and evolocumab [42], respectively, had Friedewald-estimated LDLC levels $<25 \mathrm{mg} / \mathrm{dL}$. Applying the findings from this study, we can estimate that approximately four in five patients actually could have had LDL-C levels $\geq 25 \mathrm{mg} / \mathrm{dL}$.

As clinical practice moves towards lower LDL-C levels than ever before with the availability of new cholesterol lowering drugs, our findings will tend to have greater clinical relevance. The size of the present study and methodological approach, detailing accuracy of estimation across multiple clinically relevant reference categories, adds to prior work. We suggest that an update to the current de facto LDL-C assessment will likely be crucial for personalized clinical decision-making, clinical trial design, and adverse event monitoring and prevention.

\section{Potential alternatives to Friedewald LDL-C}

If an accurate method for directly measuring LDL-C was widely available, or at least widely scalable, that could be a simple solution, assuming reasonable cost. However, no such method exists. Since the introduction of the Friedewald equation, multiple chemical based assays for direct LDL-C measurement have been introduced, but do not appear to provide an improvement [19-22]. These assays show non-specificity toward abnormal lipoproteins and fail to meet accuracy standards in diseased individuals. While ultracentrifugation was used to assess some participant samples in PCSK9 inhibitor trials, this was for research purposes only and cannot be practically implemented in clinical practice, as noted in the FDA proceedings [40].

In this context, a more accurate estimate of LDL-C is desirable from both a cost and accuracy perspective. Although multiple other groups have proposed alternative methods for LDL-C estimation, our novel LDL-C estimation appears most accurate [27] and is best validated. The performance is consistent across TG levels, the main component of the lipid profile that varies with fasting, and novel LDL-C requires no additional testing. The method can be implemented by incorporation into laboratory information technology systems for automated 
reporting, via Excel and Stata software available for free download at ldlcalculator.com, or via the Johns Hopkins LDL-C Calculator smartphone app that is freely available for iOS and Android.

While LDL-C is the focus of most clinical practice guidelines and clinical trials, non-HDL-C and apolipoprotein $\mathrm{B}$ are also included in some guidelines and warrant consideration for guiding treatment. However, clinicians are not as familiar with these [39] and clinically relevant reference values for efficacy and safety assessment at very low levels have not been established. Moreover, their responsiveness to more intensive lipid-lowering agents like PCSK9 inhibitors differs from LDL-C.

\section{Limitations}

Limitations of our database have been discussed previously in detail [27], the main limitation being the lack of clinical, medication, or demographic information other than age and sex. However, lipid distributions closely match a nationally representative US survey (NHANES) [27]. Individuals with $\mathrm{TG}<400 \mathrm{mg} / \mathrm{dL}$ were excluded in this study as it is well-known that LDL-C estimation is highly inaccurate in this setting and the clinical priority is managing hypertriglyceridemia. Moreover, the samples in this study were obtained for clinical purposes and thereby include a mix of fasting and non-fasting samples. Friedewald estimation may have performed better if only fasting samples had been included; however, inclusion of non-fasting assessments is representative of current clinical practice in Europe [43] and the US [44]. Given that novel LDL-C estimation showed more stable performance across TG levels, it may be more suitable for both fasting and non-fasting lipid assessment. Finally, external validation of our results are required; in particular, similar analyses would be of interest in patients treated with high-intensity statin therapy with or without PCSK9 inhibitors given the high proportion of individuals with very low LDL-C levels and the availability of direct ultracentrifugation measurement in subsamples of trial participants.

\section{Conclusion}

In patients with very low LDL-C levels, the lower the level, the more inaccurate the estimate, especially via Friedewald estimation. More often than not, a Friedewald estimate < $40 \mathrm{mg} / \mathrm{dL}$ is falsely low, as are the vast majority of values $<25$ and $<15 \mathrm{mg} / \mathrm{dL}$. A more accurate method of estimation, such as our novel method, is needed to improve personalized clinical decision-making and assessment of potential adverse effects in the upcoming era of cholesterol management that may witness the attainment of LDL-C levels lower than ever seen before.

\section{Additional files}

Additional file 1: Figure S1. Bland-Altman plot for $L D L-C$ in individuals with very low LDL-C levels. The Bland-Altman plot illustrates the difference against the average of directly-measured (LDLd-C) and estimation methods. Panel A: Friedewald-estimated LDL-C (LDLf-C). Standard Deviation (SD): 6.8 mg/dl. Panel B: Novel method-estimated LDL-C (LDLn-C). Standard Deviation (SD): $4.1 \mathrm{mg} / \mathrm{dl}$. (JPG $114 \mathrm{~kb}$ )

Additional file 2: Table S1. Proportions of concordance between Friedewald equation and direct ultracentrifugation LDL-C in individuals with TG < 150, 150-199, and 200-399 mg/dL. (DOCX 144 kb)

Additional file 3: Table S2. Proportions of concordance between novel method and direct ultracentrifugation LDL-C in individuals with TG $<150$, 150-199, and 200-399 mg/dL. (DOCX 137 kb)

\section{Acknowledgments}

Not applicable.

\section{Funding}

The Very Large Database of Lipids is supported by a charitable gift from the David and June Trone Family Foundation. Dr. Martin has research support from the PJ Schafer Cardiovascular Research Fund, American Heart Association, Aetna Foundation, CASCADE FH, Google, and Apple.

\section{Availability of data and materials}

The datasets used and/or analyzed during the current study available from the corresponding author on reasonable request.

\section{Authors' contributions}

$R Q$ analyzed data and interpreted the results. $R Q, A H, M B E, S R J$, and SS drafted the initial proposal and subsequent manuscript. All authors read, critically edited and approved the final manuscript.

\section{Competing interests}

Dr. Blaha has served on an advisory board for Pfizer. Dr. Toth has received compensation for consultancy and lectures from Abbvie, Aegerion, Amgen, AstraZeneca, Glaxo-SmithKline, Kowa, Merck \& Co, Novartis, and Regeneron. Dr. Banach has served on advisory boards for Amgen and Sanofi; he has lectured, attended conferences, and participated in studies sponsored by MSD, Abbott, Amgen, and Sanofi. Dr. Kulkarni has worked as an employee of Atherotech Diagnostics Laboratory and receives modest royalty from the University of Alabama in Birmingham, AL. Drs. Martin and Jones are listed as co-inventors on a pending patent filed by Johns Hopkins University for the novel method of low-density lipoprotein cholesterol estimation. Dr. Jones has served as an advisor to Sanofi/Regeneron. Dr. Martin has served as a consultant to Abbott Nutrition, Pressed Juicery, Quest Diagnostics, Sanofi/Regeneron, Amgen, and the Pew Research Center. The other authors report no conflicts.

Ethics approval and consent to participate

Not applicable.

\section{Publisher's Note}

Springer Nature remains neutral with regard to jurisdictional claims in published maps and institutional affiliations.

\section{Author details}

${ }^{1}$ Ciccarone Center for the Prevention of Heart Disease, Division of Cardiology, Department of Medicine, Johns Hopkins University School of Medicine, 600 N. Wolfe Street, Carnegie 591, Baltimore, MD 21287, USA. ²Department of Medicine, Medstar Good Samaritan/Union Memorial Hospital, Baltimore, MD, USA. ${ }^{3}$ Department of Cardiovascular Medicine, Cleveland Clinic, Cleveland, $\mathrm{OH}$, USA. ${ }^{4}$ Welch Center for Prevention, Epidemiology, and Clinical Research, Department of Epidemiology, Johns Hopkins Bloomberg School of Public Health, Baltimore, MD, USA. ${ }^{5}$ Department of Hypertension, Chair of Nephrology and Hypertension, Medical University of Lodz, Lodz, Poland. ${ }^{6}$ Atherotech Diagnostics Laboratory, Birmingham, AL, USA. ${ }^{7}$ Department of Preventive Cardiology, CGH Medical Center, Sterling, IL, USA. ${ }^{8}$ University of Illinois College of Medicine, Peoria, IL, USA. 
Received: 28 November 2016 Accepted: 4 April 2017 Published online: 20 April 2017

\section{References}

1. Cohen JC, Boerwinkle E, Mosley Jr TH, Hobbs HH. Sequence variations in PCSK9, low LDL, and protection against coronary heart disease. N Engl J Med. 2006:354(12):1264-72.

2. Ference BA, Yoo W, Alesh I, Mahajan N, Mirowska KK, Mewada A, Kahn J, Afonso L, Williams Sr KA, Flack JM. Effect of long-term exposure to lower low-density lipoprotein cholesterol beginning early in life on the risk of coronary heart disease: a Mendelian randomization analysis. J Am Coll Cardiol. 2012;60(25):2631-9.

3. Yusuf S, Hawken S, Ounpuu S, Dans T, Avezum A, Lanas F, McQueen M, Budaj A, Pais P, Varigos J, et al. Effect of potentially modifiable risk factors associated with myocardial infarction in 52 countries (the INTERHEART study): case-control study. Lancet. 2004;364(9438):937-52.

4. Mills EJ, Wu P, Chong G, Ghement I, Singh S, Akl EA, Eyawo O, Guyatt G, Berwanger O, Briel M. Efficacy and safety of statin treatment for cardiovascular disease: a network meta-analysis of 170,255 patients from 76 randomized trials. QJM. 2011;104(2):109-24.

5. Baigent C, Keech A, Kearney PM, Blackwell L, Buck G, Pollicino C, Kirby A, Sourjina T, Peto R, Collins R, et al. Efficacy and safety of cholesterol-lowering treatment: prospective meta-analysis of data from 90,056 participants in 14 randomised trials of statins. Lancet. 2005;366(9493):1267-78.

6. Taylor F, Huffman MD, Macedo AF, Moore TH, Burke M, Davey Smith G, Ward K, Ebrahim S. Statins for the primary prevention of cardiovascular disease. Cochrane Database Syst Rev. 2013;1:CD004816.

7. Boekholdt SM, Hovingh GK, Mora S, Arsenault BJ, Amarenco P, Pedersen TR, LaRosa JC, Waters DD, DeMicco DA, Simes RJ, et al. Very low levels of atherogenic lipoproteins and the risk for cardiovascular events: a metaanalysis of statin trials. J Am Coll Cardiol. 2014;64(5):485-94.

8. Anderson TJ, Gregoire J, Hegele RA, Couture P, Mancini GB, McPherson R, Francis GA, Poirier P, Lau DC, Grover S, et al. 2012 update of the Canadian Cardiovascular Society guidelines for the diagnosis and treatment of dyslipidemia for the prevention of cardiovascular disease in the adult. Can J Cardiol. 2013;29(2):151-67.

9. European Association for Cardiovascular P, Rehabilitation, Reiner Z, Catapano AL, De Backer G, Graham I, Taskinen MR, Wiklund O, Agewall S, Alegria E, et al. ESC/EAS Guidelines for the management of dyslipidaemias: the Task Force for the management of dyslipidaemias of the European Society of Cardiology (ESC) and the European Atherosclerosis Society (EAS). Eur Heart J. 2011;32(14):1769-818.

10. Jacobson TA, Ito MK, Maki KC, Orringer CE, Bays HE, Jones PH, McKenney JM, Grundy SM, Gill EA, Wild RA, et al. National Lipid Association recommendations for patient-centered management of dyslipidemia: part 1 - executive summary. J Clin Lipidol. 2014;8(5):473-88.

11. Cannon CP, Blazing MA, Giugliano RP, McCagg A, White JA, Theroux P, Darius $H$, Lewis BS, Ophuis TO, Jukema JW, et al. Ezetimibe added to statin therapy after acute coronary syndromes. New England J Med. 2015:372(25):2387-97.

12. Sabatine MS, Giugliano RP, Wiviott SD, Raal FJ, Blom DJ, Robinson J, Ballantyne CM, Somaratne R, Legg J, Wasserman SM, et al. Efficacy and safety of evolocumab in reducing lipids and cardiovascular events. N Engl J Med. 2015;372(16):1500-9.

13. Robinson JG, Farnier M, Krempf M, Bergeron J, Luc G, Averna M, Stroes ES, Langslet G, Raal FJ, El Shahawy M, et al. Efficacy and safety of alirocumab in reducing lipids and cardiovascular events. N Engl J Med. 2015;372(16):1489-99.

14. Cainzos-Achirica M, Martin SS, Cornell JE, Mulrow CD, Guallar E. PCSK9 inhibitors: a new era in lipid-lowering treatment? Ann Intern Med. 2015; 163(1):64-5.

15. Swiger KJ, Martin SS. PCSK9 inhibitors and neurocognitive adverse events: exploring the FDA directive and a proposal for N-of-1 trials. Drug Saf. 2015; 38(6):519-26.

16. Lipinski MJ, Benedetto U, Escarcega RO, Biondi-Zoccai G, Lhermusier T, Baker NC, Torguson R, Brewer Jr HB, Waksman R. The impact of proprotein convertase subtilisin-kexin type 9 serine protease inhibitors on lipid levels and outcomes in patients with primary hypercholesterolaemia: a network meta-analysis. Eur Heart J. 2016;37(6):536-45.

17. Stone NJ, Robinson JG, Lichtenstein AH, Bairey Merz CN, Blum CB, Eckel RH, Goldberg AC, Gordon D, Levy D, Lloyd-Jones DM, et al. 2013 ACC/AHA guideline on the treatment of blood cholesterol to reduce atherosclerotic cardiovascular risk in adults: a report of the American College of Cardiology/ American Heart Association Task Force on Practice Guidelines. Circulation. 2014;129(25 Suppl 2):S1-45.

18. Food and Drug Administration. Center for Drug Evaluation and Research. The Endocrinologic and Metabolic Drugs Advisory Committee Meeting. Briefing Document. Praluent (alirocumab) injection. 2015. http://www.fda. gov/downloads/AdvisoryCommittees/CommitteesMeetingMaterials/Drugs/ EndocrinologicandMetabolicDrugsAdvisoryCommittee/UCM449865.pdf. Accessed 28 Nov 2016.

19. Miller WG, Waymack PP, Anderson FP, Ethridge SF, Jayne EC. Performance of four homogeneous direct methods for LDL-cholesterol. Clin Chem. 2002; 48(3):489-98.

20. Miller WG, Myers GL, Sakurabayashi I, Bachmann LM, Caudill SP, Dziekonski A, Edwards S, Kimberly MM, Korzun WJ, Leary ET, et al. Seven direct methods for measuring HDL and LDL cholesterol compared with ultracentrifugation reference measurement procedures. Clin Chem. 2010; 56(6):977-86.

21. Davidson M, Liu SX, Barter P, Brinton EA, Cannon CP, Gotto Jr AM, Leary ET, Shah S, Stepanavage M, Mitchel Y, et al. Measurement of LDLC after treatment with the CETP inhibitor anacetrapib. J Lipid Res. 2013. 54(2):467-72

22. Ordonez-Llanos J, Wagner AM, Bonet-Marques R, Sanchez-Quesada JL, Blanco-Vaca F, Gonzalez-Sastre F. Which cholesterol are we measuring with the Roche direct, homogeneous LDL-C Plus assay? Clin Chem. 2001;47(1):124-6.

23. Friedewald WT, Levy RI, Fredrickson DS. Estimation of the concentration of low-density lipoprotein cholesterol in plasma, without use of the preparative ultracentrifuge. Clin Chem. 1972;18(6):499-502.

24. Martin SS, Blaha MJ, Elshazly MB, Brinton EA, Toth PP, McEvoy JW, Joshi PH, Kulkarni KR, Mize PD, Kwiterovich PO, et al. Friedewald-estimated versus directly measured low-density lipoprotein cholesterol and treatment implications. J Am Coll Cardiol. 2013;62(8):732-9.

25. Scharnagl $H$, Nauck $M$, Wieland $H$, Marz W. The Friedewald formula underestimates LDL cholesterol at low concentrations. Clin Chem Lab Med. 2001;39(5):426-31.

26. Meeusen JW, Snozek CL, Baumann NA, Jaffe AS, Saenger AK. Reliability of calculated low-density lipoprotein cholesterol. Am J Cardiol. 2015; 116(4):538-40.

27. Martin SS, Blaha MJ, Elshazly MB, Toth PP, Kwiterovich PO, Blumenthal RS, Jones SR. Comparison of a novel method vs the Friedewald equation for estimating low-density lipoprotein cholesterol levels from the standard lipid profile. JAMA. 2013;310(19):2061-8.

28. Martin SS, Blaha MJ, Toth PP, Joshi PH, McEvoy JW, Ahmed HM, Elshazly MB, Swiger KJ, Michos ED, Kwiterovich PO, et al. Very large database of lipids: rationale and design. Clin Cardiol. 2013;36(11):641-8.

29. Kulkarni KR. Cholesterol profile measurement by vertical auto profile method. Clin Lab Med. 2006;26(4):787-802.

30. Chung BH, Segrest JP, Cone JT, Pfau J, Geer JC, Duncan LA. High resolution plasma lipoprotein cholesterol profiles by a rapid, high volume semiautomated method. J Lipid Res. 1981;22(6):1003-14.

31. Cone JT, Segrest JP, Chung BH, Ragland JB, Sabesin SM, Glasscock A. Computerized rapid high resolution quantitative analysis of plasma lipoproteins based upon single vertical spin centrifugation. J Lipid Res. 1982;23(6):923-35.

32. Meeusen JW, Lueke AJ, Jaffe AS, Saenger AK. Validation of a proposed novel equation for estimating LDL cholesterol. Clin Chem. 2014;60(12):1519-23.

33. Lee J, Jang S, Son H. Validation of the Martin method for estimating lowdensity lipoprotein cholesterol levels in Korean adults: findings from the Korea National Health and Nutrition Examination Survey, 2009-2011. PLoS One. 2016;11(1):e0148147.

34. Jarcho JA, Keaney Jr JF. Proof that lower is better-LDL cholesterol and IMPROVE-IT. N Engl J Med. 2015;372(25):2448-50.

35. Navarese EP, Kolodziejczak M, Schulze V, Gurbel PA, Tantry U, Lin Y, Brockmeyer M, Kandzari DE, Kubica JM, D'Agostino Sr RB, et al. Effects of proprotein convertase subtilisin/kexin type 9 antibodies in adults with hypercholesterolemia: a systematic review and meta-analysis. Ann Intern Med. 2015;163(1):40-51.

36. The Evaluation of Bococizumab (PF-04950615:RN316) in Reducing the Occurrence of Major Cardiovascular Events in High Risk Subjects (SPIRE-1). ClinicalTrials.gov: NCT01975376. https://clinicaltrials.gov/ct2/show/ NCT01975376. Accessed 13 Dec 2015. 
37. The Evaluation of Bococizumab (PF-04950615; RN316) in Reducing the Occurrence of Major Cardiovascular Events in High Risk Subjects (SPIRE-2). ClinicalTrials.gov: NCT01975389. https://clinicaltrials.gov/ct2/show/ NCT01975389. Accessed 13 Dec 2015.

38. Smith JP. Food and Drug Administration. Center for Drug Evaluation and Research. The Endocrinologic and Metabolic Drugs Advisore Committee Meeting. Briefing Document. Repatha (evolocumab) injection. 2015. http:// www.fda.gov/downloads/AdvisoryCommittees/CommitteesMeetingMaterials/ Drugs/EndocrinologicandMetabolicDrugsAdvisoryCommittee/UCM450072.pdf. Accessed 28 Nov 2016.

39. Negi SI, Steinberg L, Polsani VR, Gowani SA, Nambi V, Kumar V, Marinescu V Jones PH, Petersen LA, Ballantyne CM, et al. Non-high-density lipoprotein cholesterol calculation and goal awareness among physicians-in-training. J Clin Lipidol. 2012;6(1):50-7.

40. Wiviott SD, Cannon CP, Morrow DA, Ray KK, Pfeffer MA, Braunwald E, Investigators PI-T. Can low-density lipoprotein be too low? The safety and efficacy of achieving very low low-density lipoprotein with intensive statin therapy: a PROVE IT-TIMI 22 substudy. J Am Coll Cardiol. 2005;46(8):1411-6.

41. Everett BM, Mora S, Glynn RJ, MacFadyen J, Ridker PM. Safety profile of subjects treated to very low low-density lipoprotein cholesterol levels ( $<30 \mathrm{mg} / \mathrm{dl}$ ) with rosuvastatin $20 \mathrm{mg}$ daily (from JUPITER). Am J Cardiol. 2014:114(11):1682-9.

42. Food and Drug Administration Center for Drug Evaluation and Research. The Endocrinologic and Metabolic Drugs Advisory Committee Meeting: Briefing Document, Repatha (evolocumab) injection. http://www.fda.gov/ downloads/AdvisoryCommittees/CommitteesMeetingMaterials/Drugs/ EndocrinologicandMetabolicDrugsAdvisoryCommittee/UCM450072.pdf. Accessed 5 Sep 2016.

43. Nordestgaard BG, Langsted A, Mora S, Kolovou G, Baum H, Bruckert E, Watts GF, Sypniewska G, Wiklund O, Borén J, Chapman MJ, Cobbaert C, Descamps OS, von Eckardstein A, Kamstrup PR, Pulkki K, Kronenberg F, Remaley AT, Rifai N, Ros E, Langlois M, European Atherosclerosis Society (EAS), the European Federation of Clinical Chemistry, Laboratory Medicine (EFLM) joint consensus initiative. Fasting is not routinely required for determination of a lipid profile: clinical and laboratory implications including flagging at desirable concentration cut-points-a joint consensus statement from the European Atherosclerosis Society and European Federation of Clinical Chemistry and Laboratory Medicine. Eur Heart J. 2016;37:1944-58.

44. Driver SL, Martin SS, Gluckman TJ, Clary JM, Blumenthal RS, Stone NJ. Fasting or nonfasting lipid measurements: It depends on the question. J Am Coll Cardiol. 2016;67:1227-34.

\section{Submit your next manuscript to BioMed Central and we will help you at every step:}

- We accept pre-submission inquiries

- Our selector tool helps you to find the most relevant journal

- We provide round the clock customer support

- Convenient online submission

- Thorough peer review

- Inclusion in PubMed and all major indexing services

- Maximum visibility for your research

Submit your manuscript at www.biomedcentral.com/submit

) Biomed Central 